'Under the Mediterranean' The Honor Frost Foundation Conference on Mediterranean Maritime Archaeology 20th $-23_{\text {rd }}$ October 2017 Short Report Series.

doi: https://doi.org/10.33583/utm2020.03

(C) 2020 The Author

\title{
Virtual Reality and Virtual Dives among Sicilian Marble Cargos
}

\author{
E. Costa, S. Manfiob, S. Tusa $\dagger_{\mathrm{c}}$
}

a Università Iuav di Venezia, ecosta@iuav.it

ьCa' Foscari Università di Venezia, stefaniamanfio@gmail.com

c Soprintendenza del Mare - Regione Siciliana, sopmare@ regione.sicilia.it

In this paper, we describe the elaboration phases related to virtual models and virtual reality (VR) of a wide project on "The routes of the marble" directed by Carlo Beltrame of the Dipartimento di Studi Umanistici of $\mathrm{Ca}$ ' Foscari University in collaboration with the Soprintendenza del Mare - Regione Siciliana. Immersive VR is based on Real Time Render technology, thanks to which the users can immerse themselves in situations characterised by a simulated reality, with a strong sensation of immersion. These technologies have been applied on the Isola delle Correnti and Cape Granitola shipwrecks investigated and documented over the last few years by our team.

\section{Key words}

Maritime archaeology, Marble cargos, Photogrammetry, Shipwrecks, Sicily, Virtual Reality

Nowadays, new optical approaches and technologies, as Virtual and Augmented Reality, are widely employed in archaeology and support studies and documentation of researchers, in order to make available cultural heritage, such as ancient shipwrecks and underwater sites. Immersive Reality allows the users to virtually immerse themselves in the underwater archaeological site in its real and landscape context. In the field of Underwater Cultural Heritage, the VR technologies have been applied mainly to the reconstruction of underwater archaeological sites in order to get information about the shipwrecks and their cargos, such as the Mazotos shipwreck of the iMare Culture project (Demesticha et al., 2014; Liarokapis et al., 2017). 
The potential of VR allows us to create projects with an edutainment-oriented approach, in which the users' cultural awareness is increased due to the real reconstruction of all connected elements of the maritime archaeological site (shipwreck, environment and dive). An example of this approach is the VISAS project, where the Cala Minnola shipwreck and the underwater landscape are faithfully recreated, as well as the simulation of a real diving session from the point of view of a scuba diver (Bruno et al., 2017). This kind of design of the virtual tour allows the user to combine an educational purpose, learning archaeological and historical information, with an amusing activity, being able to virtually dive and enjoy the underwater environment (Bruno et al., 2018: 92).

Another interesting product is led by Ca' Foscari and Iuav University of Venice in collaboration with Polo Museale of Venice1; this innovative exhibition project - focused on the brick Mercurio shipwreck of 1812 will be inaugurated at the Museo Nazionale di Archeologia del Mare in Caorle, near Venice, this summer 2018. In the museum, a station was installed where the user, through Oculus Rift, could visit the shipwreck; in fact, the main aim of this project is the dissemination of underwater cultural heritage to a wider public, based on scientific research.

\section{Case studies}

We want to describe the entire workflow carried out on two underwater sites composed of marble blocks, dated to the Roman age and surveyed in 2015 and 2016. The workflow concerns the survey's design, image acquisition, topographic measurements and data processing to obtain a 3D model, suitable for different fields of application, such as scientific research and multimedia installation for dissemination to a wider public. The first shipwreck is Isola delle Correnti, near Siracusa, in South-East Sicily, which is composed of 25 squared half-carved marble blocks lying on a jagged rocky bottom, from $5 \mathrm{~m}$ to $8 \mathrm{~m}$ deep. In 1959, G. Kapitän (Kapitän, 1961) documented 40 items but 15 of these, one-third of the weight of the cargo, were not present anymore in 2016 during our survey campaign, creating a large gap in the middle of the site (Beltrame and Costa, 2017). The second one is Cape Granitola (Purpura, 1977), near Marsala, in the south-west (Balletti et al., 2015; Beltrame and Costa, 2017), which lies $4 \mathrm{~m}$ deep on a sandy bottom and is represented by a homogeneous cargo of squared marble blocks found in stowage position in parallel lines. The marble blocks are corroded and concreted but we can recognize 63 items with a squared shape and only two items with the shape of a podium.

\section{The survey and modelling of the archaeological sites}

The missions on the shipwrecks were developed in the following phases, starting from cleaning the subject of sand and vegetation; the edges and the surfaces of the blocks are hidden by seaweed and we needed to remove them to expose the right shape of the blocks. After cleaning it was possible to continue with the positioning of the Ground Control Points to rotate and scale the models of the sites into a correct reference system. We surveyed the targets with a trilateration method for the distances and with the scuba computer for

1 a publication about this topic is in progress by Beltrame C., Guerra F., Manfio S. and Secci M. 
the depths and the obtained data was processed with Site Recorder 4 software to create xyz coordinates of the targets, following the Direct Survey Method technique as a 3D topographic network (Rule, 1989).

The image acquisition phase followed the rules of the multi-image digital photogrammetric survey that is considered the most advantageous documentation technique to obtain a detailed and accurate 3D model (Drap et al., 2007; McCarthy and Benjamin, 2014). Different photogrammetric strips were realized: nadiral images, in the same way as in aerial photogrammetry, and radial and oblique images at $45^{\circ}$ to cover the vertical portion of the blocks, taking care to obtain complete coverage of the site with an overlapping of the images at around $60 \%$.

As a result of the survey, we have 3D models of the sites, from which we have extrapolated the orthophotos from a top viewpoint and a textured meshed model employed for virtual reality processing phase (figs. 1 - 2). Every single mesh of the blocks, highlighted from the seabed, has been imported into Rhinoceros software to realize the final 3D model removing the irregularity of the concretions and the seaweeds on the marble. The portion of the blocks close to the seabed and in contact with the sand was not visible in the photogrammetric model obtained and it has been integrated with the direct manual measurements to reconstruct the original shape of the blocks.

With the Isola delle Correnti shipwreck, the correct position of the stolen marble blocks in the centre of the site has been recognized from the compared map between the original plan created by Kapitaen and the one obtained from the photogrammetric and topographic survey (fig. 3). Thanks to the database of the measurements of the blocks drafted by Kapitaen, we have modelled the lost part of the archaeological site and we have inserted the reconstructed stolen blocks in the textured model of the shipwreck (fig. 4).

The blocks of the two shipwrecks have been decimated in order to reduce the size of the model, both of existing blocks and of the reconstructed ones. Existing marble blocks have been mapped with the highresolution texture created by the photogrammetric survey, which is recognisable for the blue-green dominant colour of the underwater images, instead, for the reconstructed polygonal items, as the stolen blocks and the bottom, we have used photographic textures of the material to reproduce colours and features of the original elements (figs. 5-6).

\section{The virtual reality of the sites}

To recreate the underwater archaeological sites Unreal Engine 4 software has been used, a game engine developed by Epic Games that is designed for creating virtual reality projects.

The first step of the process concerned the uploading of the 3D elaboration of the blocks, of the reconstructed items and of the sea-bottom (fig. 7). The second step concerned the creation of the virtual scene of the underwater environment: animated elements, such as fish and eels, and static objects, such as flora, have been elaborated and texturized using 3D CAD software and then have been uploaded in Unreal Engine 4. To show the typology of local seagrass and seaweed plants, we employed the Foliage technique directly on the virtual reality software. In particular, we have scattered the Poseidonia Oceanica, following the right position thanks to the images of the sites and the 3D elaboration (fig. 8). During the final step, in order to 
make the virtual underwater scenario more realistic in the visualisation, some graphical effects have been applied, such as refraction, fog, caustics and a dirty mask.

To highlight peculiar characteristics of the archaeological site and to make the virtual immersion on the wreck more interesting and educational, we have created some pop-ups on the marble blocks. When the user goes in the trigger boxes created in some points on the site, a widget automatically appears on the screen and tells us information about the cargo through images and texts (fig. 9).

Thanks to the Unreal tools, it is possible to show to the public the original and complete cargo of the wreck, integrated in the archaeological and natural environment. In the case study of the Isola delle Correnti shipwreck, the missing blocks recreated in 3D have been placed in the right position within the virtual project, thanks to the same referencing system of the complete cargo realized on Rhinoceros software (figs. 4 and 10).

The second project, based on the Capo Granitola shipwreck, has been processed in the same way: the original texturized blocks realized by Photoscan and elaborated with Rhino have been imported on UE4 and the realistic environment based on bathymetry and the Sicilian ecosystem, with local seagrass and seaweed plants created (fig. 11). Differently from the VR project of Isola delle Correnti, where the marble blocks no longer present underwater have been shown, in this shipwreck, we have decided to show a hypothetical position of the original stowage of the cargo. The action is originated by the activation of the trigger box when the diver reaches the red floating buoy (fig. 12).

In both cases, the light has been set up to reproduce the actual depth of the underwater sites and the navigation starts from the water surface, so, the user could simulate a real dive, enriching the virtual experience. The interface realized has been set up to allow the user to navigate, or "swim" through the site using the keyboard or a gamepad and we are also working on adapting these projects with the Oculus visualization, which could be installed in specific multimedia stations in different museums.

The videos of the final projects have been uploaded on a website to allow the fruition of the two shipwrecks presented in this paper.

- Isola delle Correnti shipwreck: https://youtu.be/ZKoHf_F9K0s;

- Cape Granitola shipwreck: https://youtu.be/CkpYQscKaoQ;

Moreover, we linked also the project of Cape Taormina shipwreck which is not yet completed with all interfaces, since the study of the shipwreck is still in progress.

- $\quad$ Cape Taormina shipwreck: https://youtu.be/WPIfwoJDZ64.

\section{Conclusions}

This experience aims to highlight the importance of new digital technologies from a metric and recording point of view. Photogrammetric survey is an accurate method of documentation that can be used to take measurements and verify various kinds of data (Drap et al., 2007; Eric et al., 2013); furthermore, the researchers are able to recreate a very realistic and accurate model, which offers many opportunities for interpretation and presentation of underwater archaeological sites. 
The underwater environment represents a complicated and restricted context, due to difficult access to archaeological sites. Technical limits such as deep diving or protection and conservation issues involve various problems of usability by a wide public. Moreover, the capability to create public interpretive deliverables to be implemented in museum environments allows us to share knowledge about archaeological sites and the past. Immersive Virtual Reality is going to become a new concept for museum exhibitions, in which the museum can be considered an ICT, an information and communication technology, more than a simple container of objects and artefacts.

\section{Acknowledgements}

The investigation of the Roman marble cargoes have been achieved thanks to the financial support of the Università Ca' Foscari Venezia and the Honor Frost Foundation and were permitted by the Soprintendenza del Mare (represented by Sebastiano Tusa) which collaborated in the underwater activities. We would like to thank professor Carlo Beltrame, the director of the project for granting the use of data on marble cargos.

The VR project on the Mercurio shipwreck has been realised in the project coordinated by Carlo Beltrame and Francesco Guerra "Restituzione 3D di Relitti Antichi Sommersi finalizzata alla realizzazione di Musei virtuali con realtà immersiva e aumentata", thanks to European Social Fund (ESF) funding from the Veneto region.

\section{Reference list}

Balletti, C., Beltrame, C., Costa, E., Guerra, F., Vernier, P., 2016, 3D reconstruction of marble shipwreck cargoes based on underwater multi-image photogrammetry. Digital Applications in Archaeology and Cultural Heritage 3.1, 1-8.

Beltrame, C., Costa, E., 2018, 3D survey and modelling of shipwrecks in different underwater environments. Journal of Cultural Heritage 29, 82-88.

Bruno, F., Lagudi A., Barbieri L., Muzzupappa M., Mangeruga M., Pupo F., Cozza M., Ritacco G., Peluso R., Tusa S., 2017, Virtual diving in the underwater archaeological site of Cala Minnola. ISPRS International Archives of the Photogrammetry, Remote Sensing and Spatial Information Sciences XLII2/W3, 121-26.

Bruno F., Barbieri L., Lagunari A., Cozza M., Cozza A., Peluso R., Muzzupappa M., 2018, Virtual Dives into the Underwater Archaeological Treasures of South Italy. Virtual Reality 22 (2), 91-102.

Demesticha, S., Skarlatos, D., Neophytou, A., 2014, The 4th-century B.C. shipwreck at Mazotos, Cyprus: New techniques and methodologies in the 3D mapping of shipwreck excavations, Journal of Field Archaeology, 39.2, 134-150.Drap, P., Seinturier, J.,Scaradozzi, D., Gambdogi, P., Long L., Gauch, F., 2007, 
Photogrammetry for virtual exploration of underwater archeolgical sites. ISPRS - International Archive of Photogrammetry, Remote Sensing and Spatial Information Science, XXXVI- 5/C53.

Eric, M., Kovacic, R., Berginc, G., Pugelj, M., Stopinsek, Z., Solina, F., 2013, The impact of the latest 3D technologies on the documentation of underwater heritage sites. Proceedings of the 2013 Digital Heritage International Congress 2013, 28 Oct - 1 Nov, Marseille, France: IEEE, vol. 2, 281-288.

Kapitaen, G., 1961, Schiffsfrachten antiker Baugesteine und Architekturteile vor den Kuesten Ostsiziliens, Klio 39, 276-318.

Liarokapis F., Kour il P., Agrafiotis P., Demesticha S., Chmelı'k J., Skarlatos D., 2017, 3D modelling and mapping for virtual exploitation of underwater archaeology assets. Int Arch Photogramm Remote Sens Spat Inf Sci XLII-2/W3, 425-431.

McCarthy, J., Benjamin, J., 2014, Multi-image photogrammetry for underwater archaeological site recording: an accessible, diver-based approach. Journal of Maritime Aarchaeology, 03/2014.

Purpura, G., 1977, Un relitto con un carico di marmo a Capo Granitola (Mazara). Sicilia Archeologica, anno $\mathrm{X}, 33$.

Rule, N., 1989, The Direct Survey Method (DSM) of underwater survey, and its application underwater. The International Journal of Nautical Archaeology, 18.2, 157-162. 


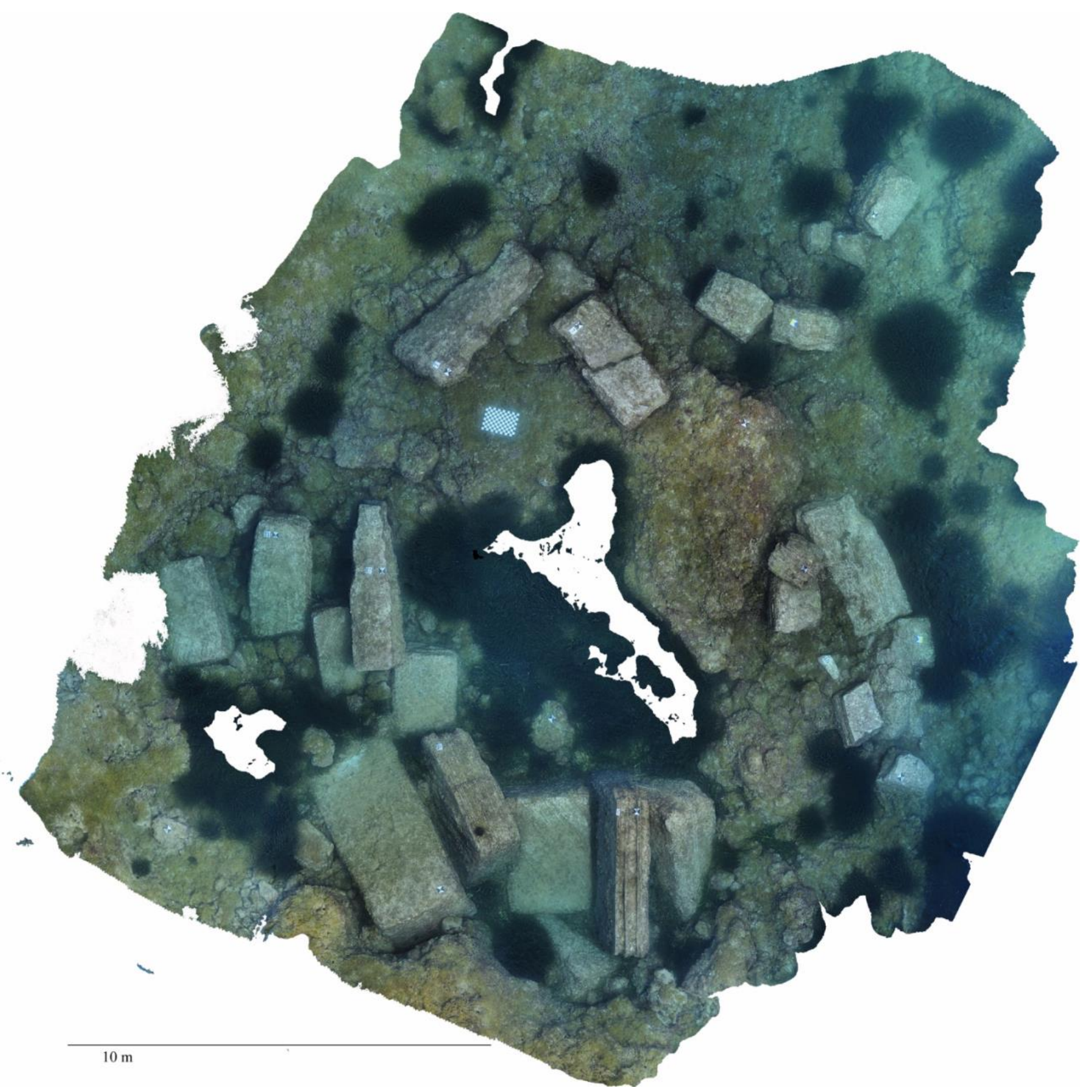

Fig. 1. Isola delle Correnti shipwreck: ortophoto of the plan. North on the top. (elaboration: E. Costa) 


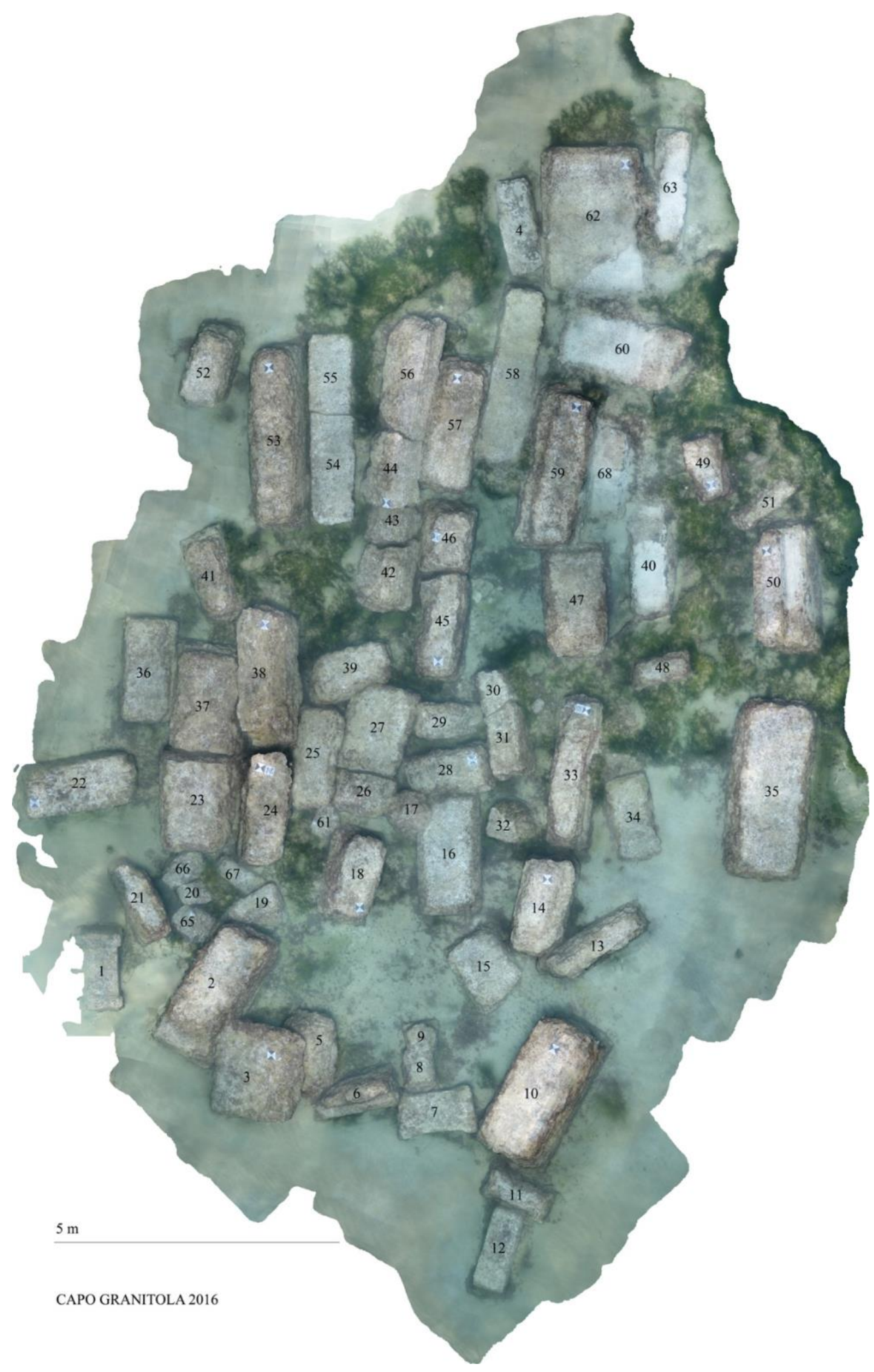

Fig. 2. Cape Granitola shipwreck: ortophoto of the plan. North on the top. (elaboration: E. Costa) 


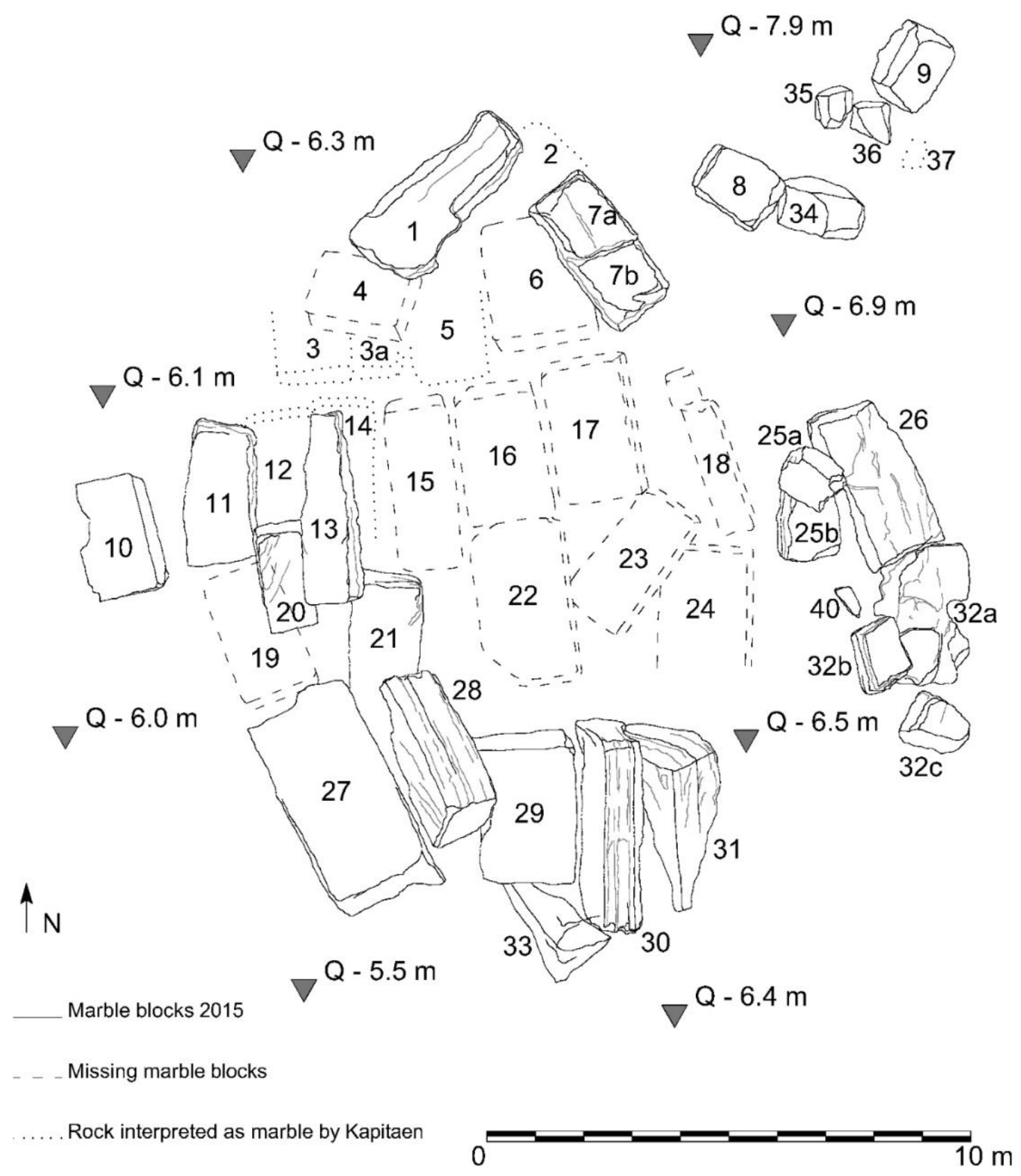

Fig. 3. Isola delle Correnti shipwreck: compared map with the existing block and the stolen ones. (elaboration: E. Costa) 


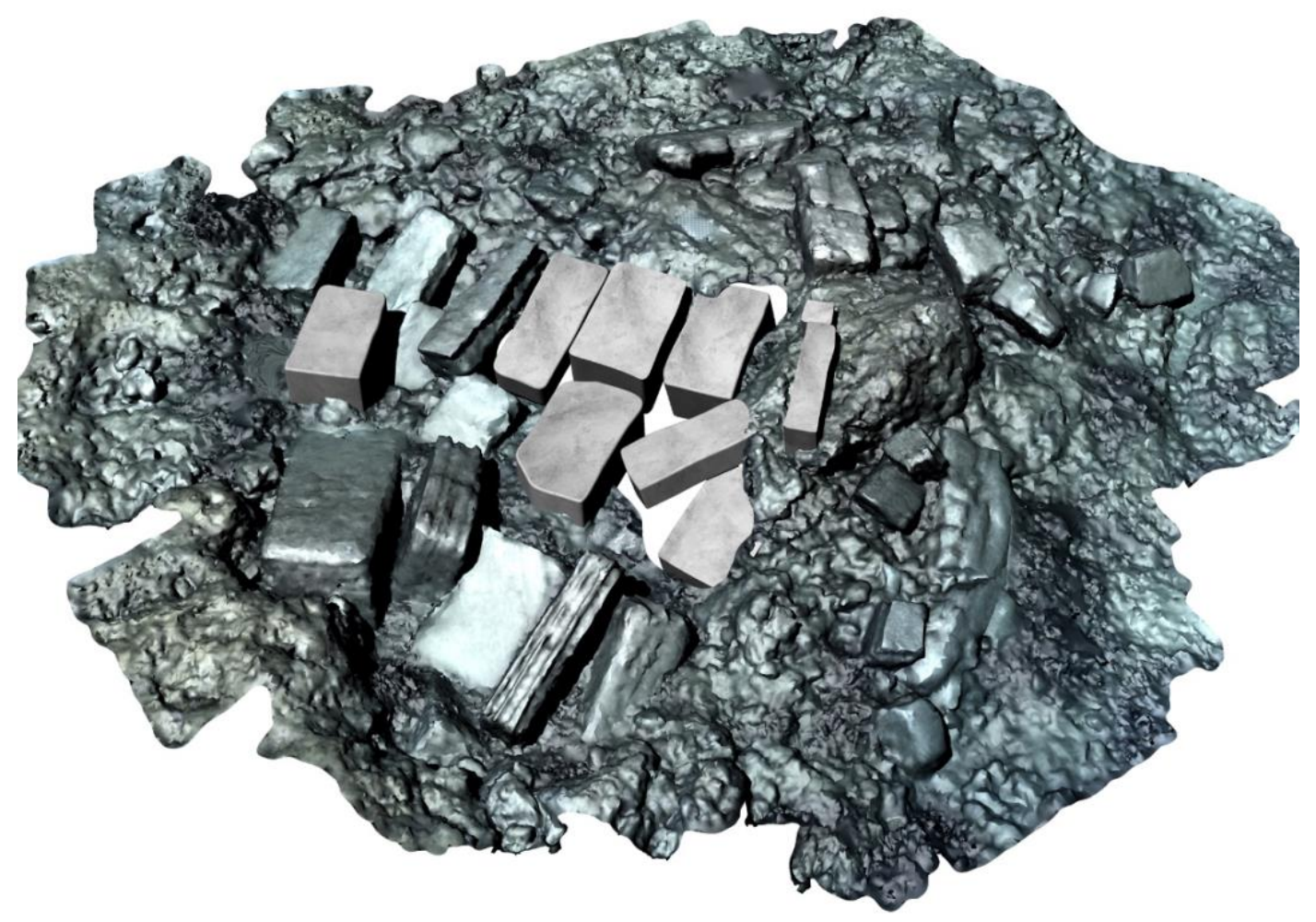

Fig. 4. Isola delle Correnti shipwreck: decimated mesh of existing blocks with the reconstruction of the stolen ones. (elaboration: E. Costa)

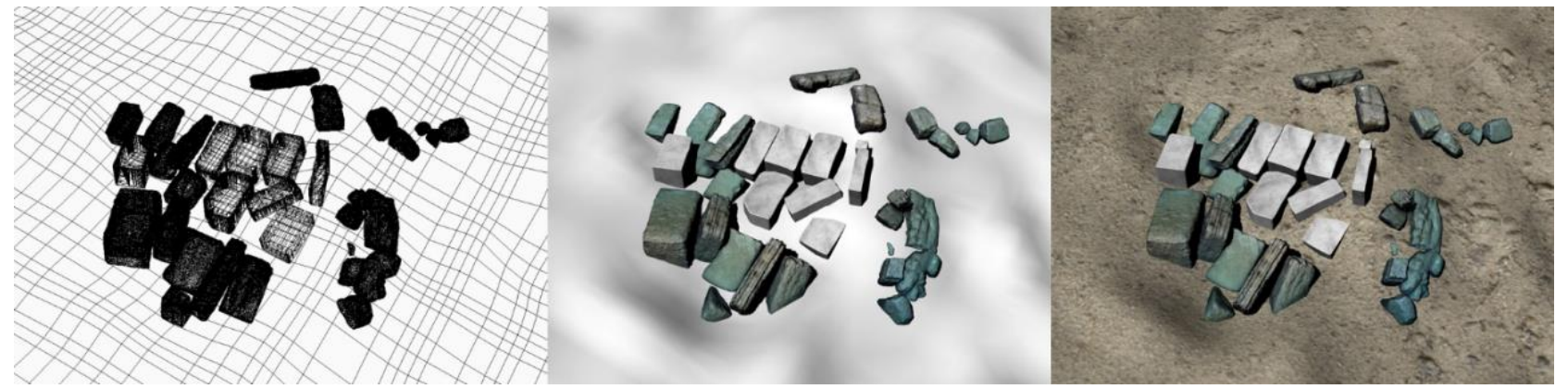

Fig. 5. Isola delle Correnti shipwreck: phases of the data processing to obtain the complete 3D model for virtual reality. (elaboration: E. Costa)

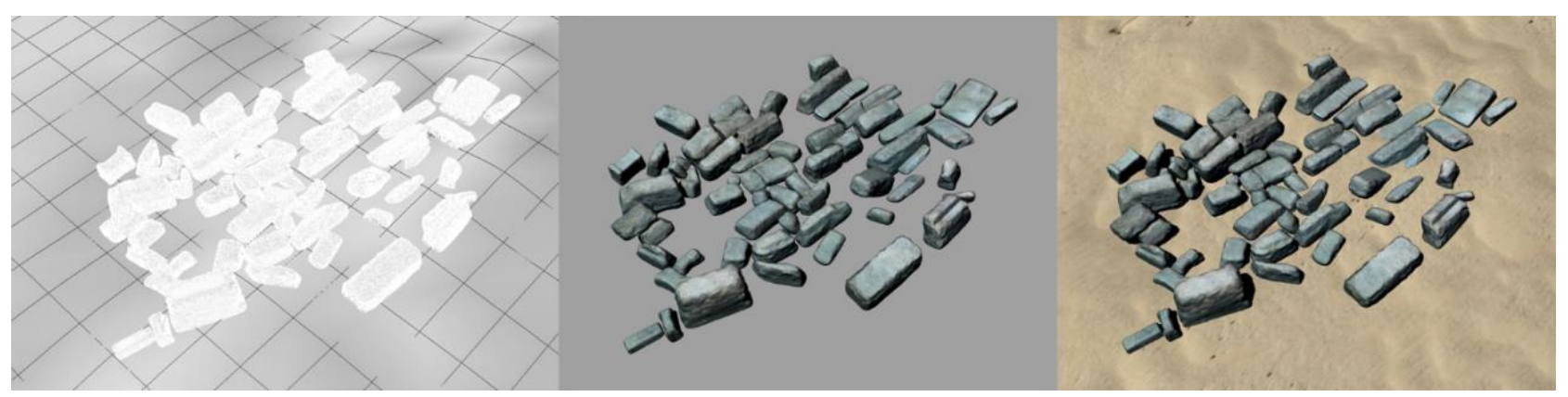

Fig. 6. Cape Granitola shipwreck: phases of the data processing to obtain the complete 3D model for virtual reality. (elaboration: E. Costa) 


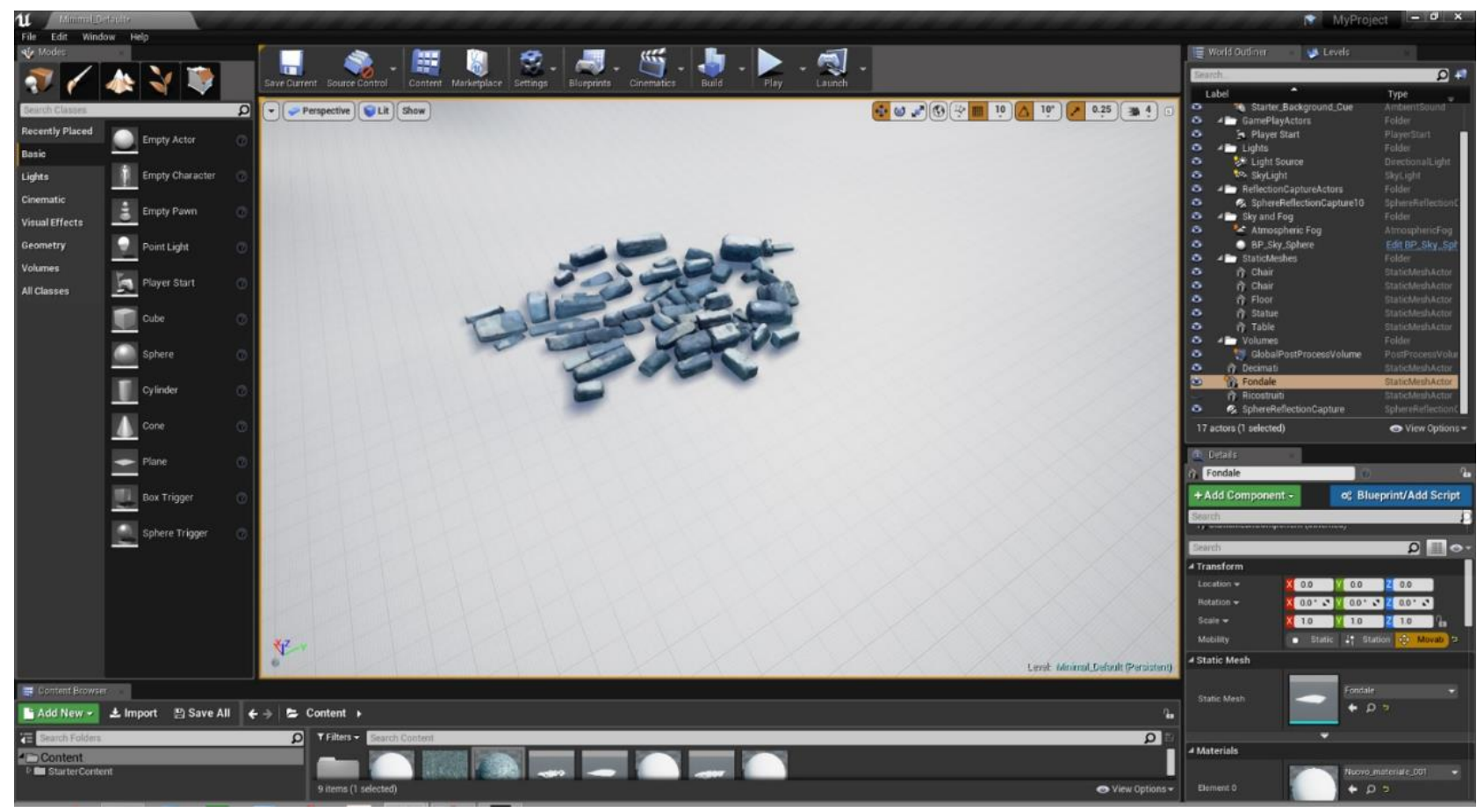

Fig. 7. Isola delle Correnti shipwreck: creation of the project in Unreal Engine 4 and upload of the 3D elaboration of the blocks. (elaboration: S. Manfio)

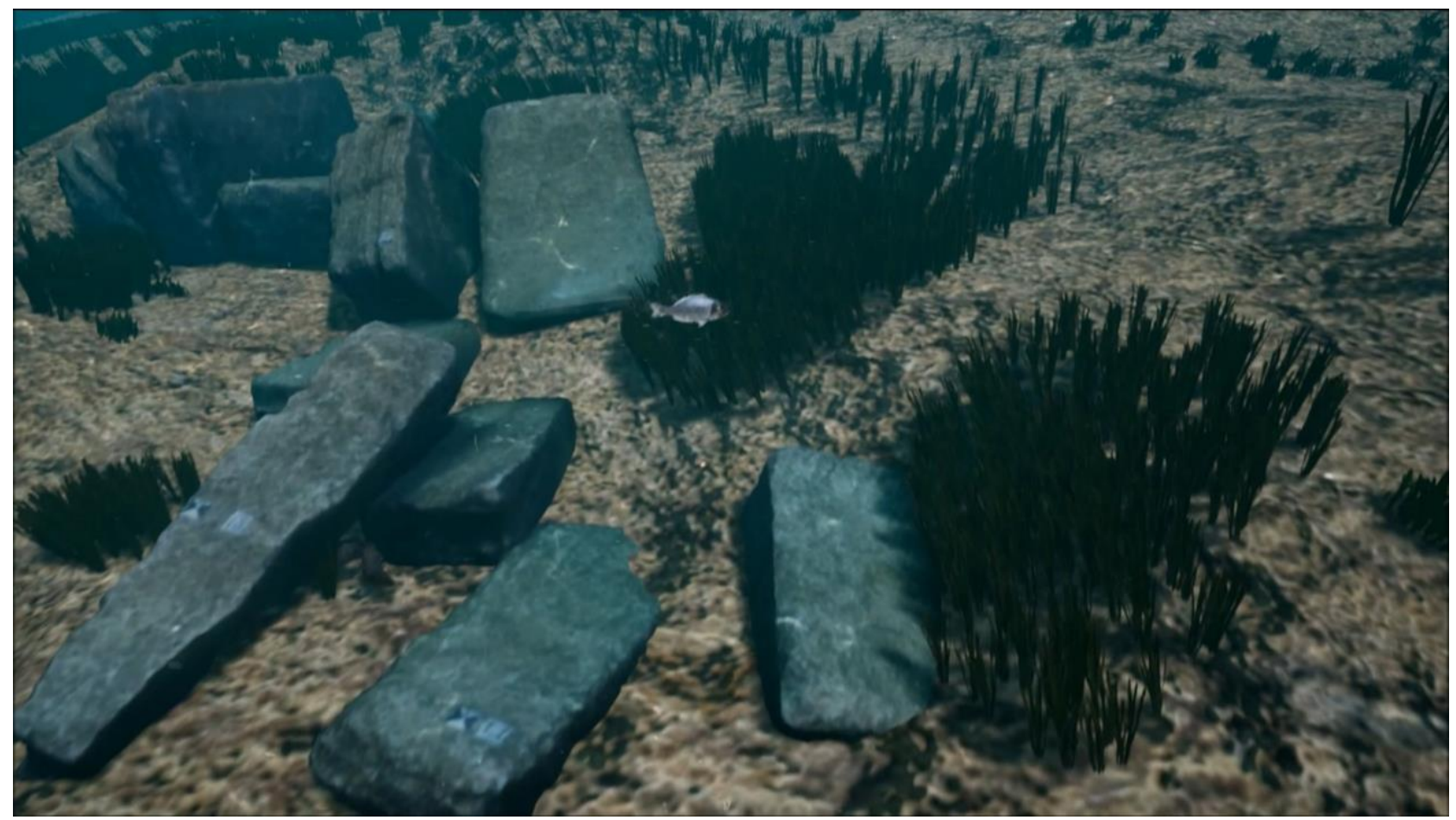

Fig. 8. Isola delle Correnti shipwreck: creation of the virtual scene of the underwater environment. (elaboration: S. Manfio) 


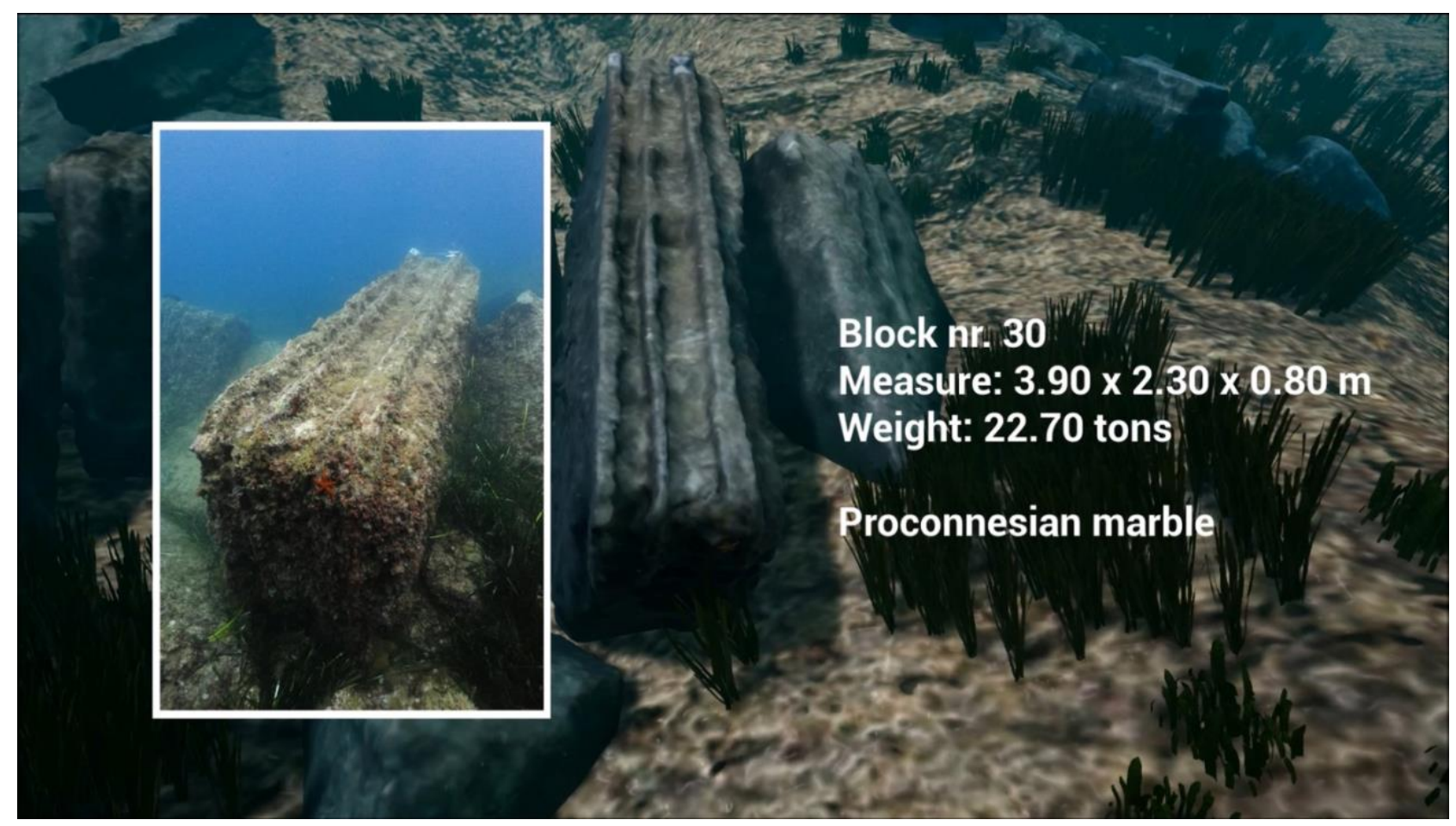

Fig. 9. Isola delle Correnti shipwreck: interface with a pop-up with information on the cargo. (elaboration: S. Manfio)

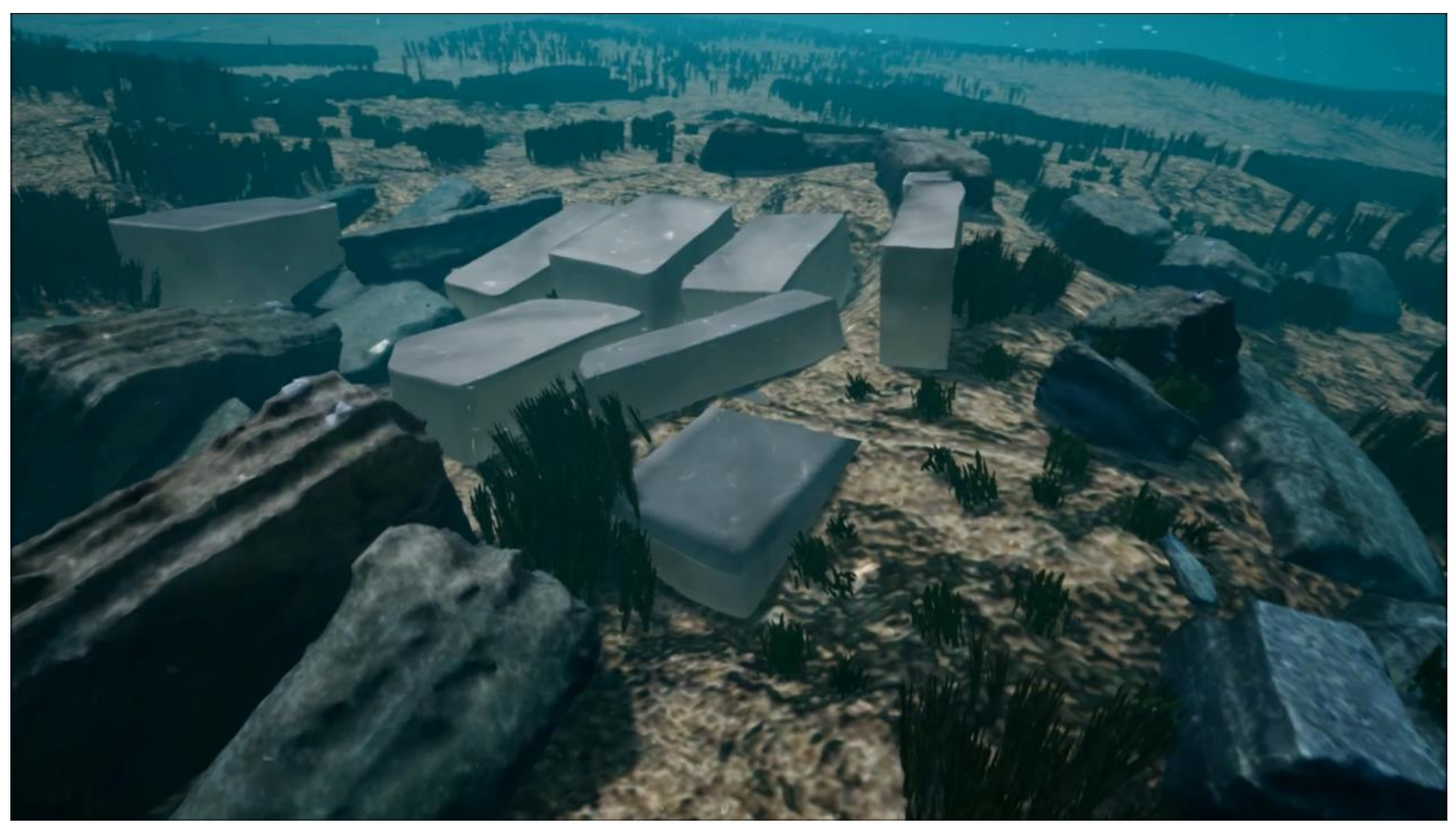

Fig. 10. Isola delle Correnti shipwreck: reconstruction of the entire site with the placement of stolen blocks. (elaboration: S. Manfio) 


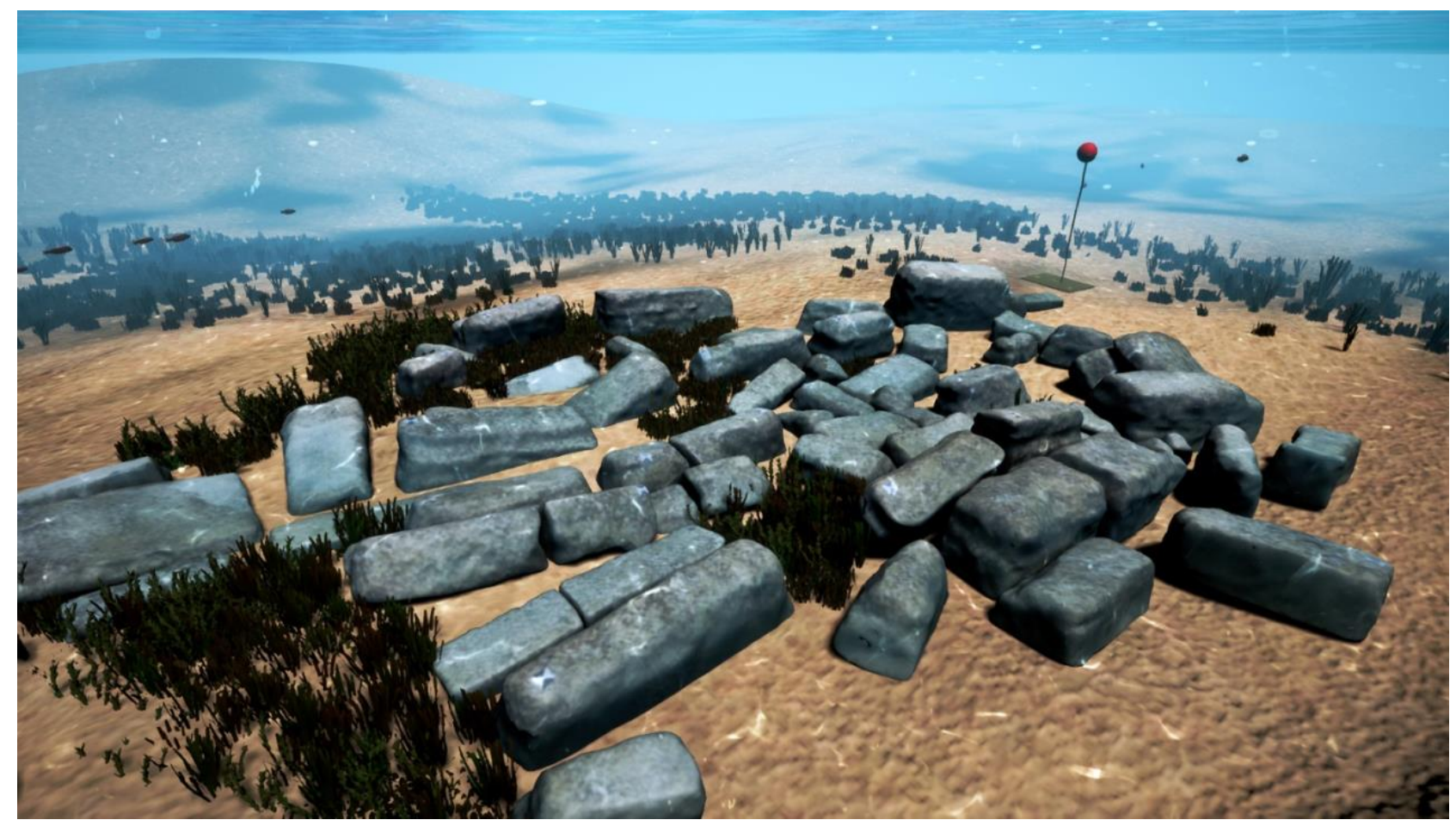

Fig. 11. Cape Granitola shipwreck: upload of the blocks and creation of the underwater environment. (elaboration: S. Manfio)

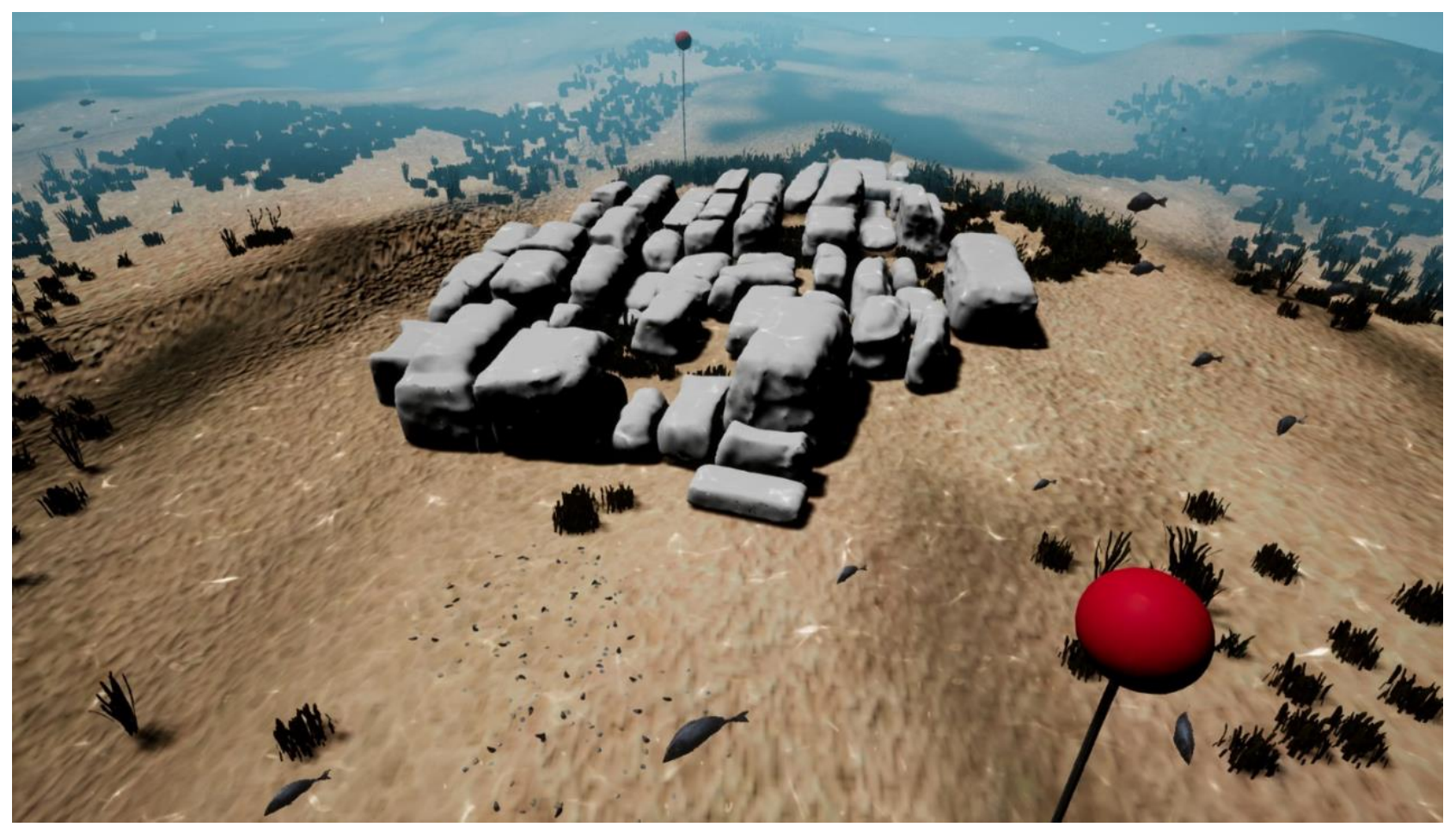

Fig. 12. Cape Granitola shipwreck: hypothetical position of the original stowage of the cargo. (elaboration: E. Costa and S. Manfio) 
